\title{
Integração e análise de dados aerogamaespectrométricos, aeromagnetométricos e SRTM como ferramenta de suporte no mapeamento geológico em área do Terreno Granito-Greenstone de Rio Maria, região de Xinguara, sudeste do Pará
}

Marcílio Cardoso Rocha*, Unifesspa - Universidade Federal do Sul e Sudeste do Pará Alberto Jacques Ribeiro Corrêa, Unifesspa - Universidade Federal do Sul e Sudeste do Pará José de Arimatéia Costa de Almeida, Unifesspa - Universidade Federal do Sul e Sudeste do Pará

Copyright 2016, SBGf - Sociedade Brasileira de Geofísica

Este texto foi preparado para a apresentação no VII Simpósio Brasileiro de Geofísica, Ouro Preto, 25 a 27 de outubro de 2016. Seu conteúdo foi revisado pelo Comitê Técnico do VII SimBGf, mas não necessariamente representa a opinião da SBGf ou de seus associados. É proibida a reprodução total ou parcial deste material para propósitos comerciais sem prévia autorização da SBGf.

\section{Abstract}

This paper aims to present the results obtained by the integration and analysis of geophysical data and Digital Elevation Model (DEM) images as an important tool in geological mapping in an area located in the Rio Maria Granite-Greenstone Terrane (RMGGT), in the Central Amazonian Province (Tassinari \& Macambira, 2004) or Carajás Province (Santos, 2003), southeastern Amazonian Craton, Xinguara area, southeastern Pará. The aerogammaspectrometric and aeromagnetometric data used for this study were acquired by the BrazilCanada Geophysical Project (PGBC) and the digital elevation images by the Shuttle Radar Topographic Mission (SRTM). The integration and analysis of these data showed to be very useful for geological mapping, specially to distinguish the different lithologies and help to select key areas for more detailed verification during the field mapping. At the end of this study, it was elaborated a geological map for the selected area.

\section{Introdução}

A integração e análise de dados multifontes é uma técnica que auxilia bastante nas atividades de mapeamento geológico (Cunha, 2002; Carneiro, 2006). Um bom exemplo disso são as imagens geradas a partir de dados geofísicos, que, quando combinadas com imagens SRTM em ambiente SIG, podem realçar informações geológicas importantes. Algumas dessas informações poderiam não ser notadas se a análise fosse feita nas imagens individualmente.

Neste trabalho foram integrados e analisados dados aerogamaespectométricos, aeromagnetométricos e dados SRTM da área de estudo. A fusão dessas imagens possibilitou que informações litológicas e estruturais se tornassem mais evidentes, servindo como um guia durante os trabalhos de campo e auxiliando na delimitação das unidades presentes na área.

A área de estudo está localizada no sudeste do estado do Pará (Figura 1), abrange parte das folhas topográficas SB-22-Z-C-III (Xinguara) e SB-22-Z-A-VI (Água Fria), possui um perímetro de aproximadamente $60 \mathrm{~km}$, área de $200 \mathrm{~km}^{2}$, e limita-se pelas seguintes coordenadas UTM: 616350.386, 9214539.029, 632940.386 e 9236806.466 .

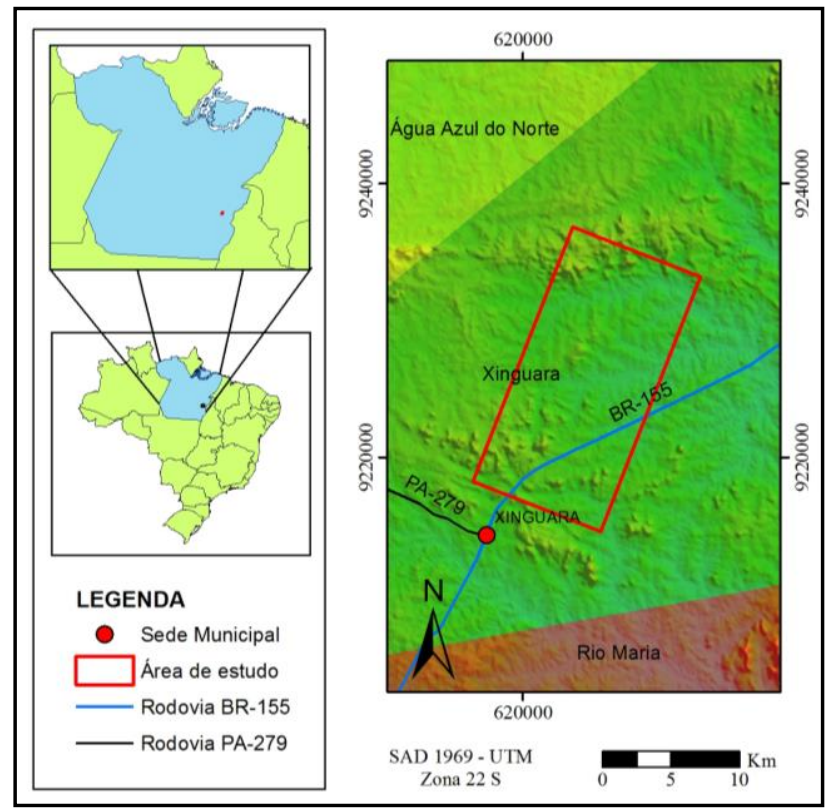

Figura 1: Mapa de localização da área de estudo.

\section{Materiais e métodos}

Os dados aerogeofísicos utilizados neste trabalho foram obtidos durante os aerolevantamentos realizados pelo Projeto Geofísico Brasil Canadá (PGBC). O espaçamento entre as linhas de voo foi de $2 \mathrm{~km}$ e o intervalo entre as medições foi de $1 \mathrm{~s}$, o que corresponde a aproximadamente 62 metros. A velocidade média do avião foi de $225 \mathrm{~km} / \mathrm{h}$. O PGBC foi resultado do convênio firmado entre o Departamento Nacional de Pesquisa Mineral (DNPM) do Ministério de Minas e Energia (MME) e a Canadian International Development Agency (CIDA). Os dados aerogeofísicos aqui utilizados foram divulgados pela CPRM em formato digital em CD ROM intitulado "GEOLOGIA E RECURSOS MINERAIS DO ESTADO DO PARÁ".

A integração dos dados consistiu basicamente na fusão de imagem SRTM com amplitude do sinal analítico (Figura 2A), bem como da fusão de imagem SRTM com canal do tório (Figura $2 \mathrm{~B}$ ). 


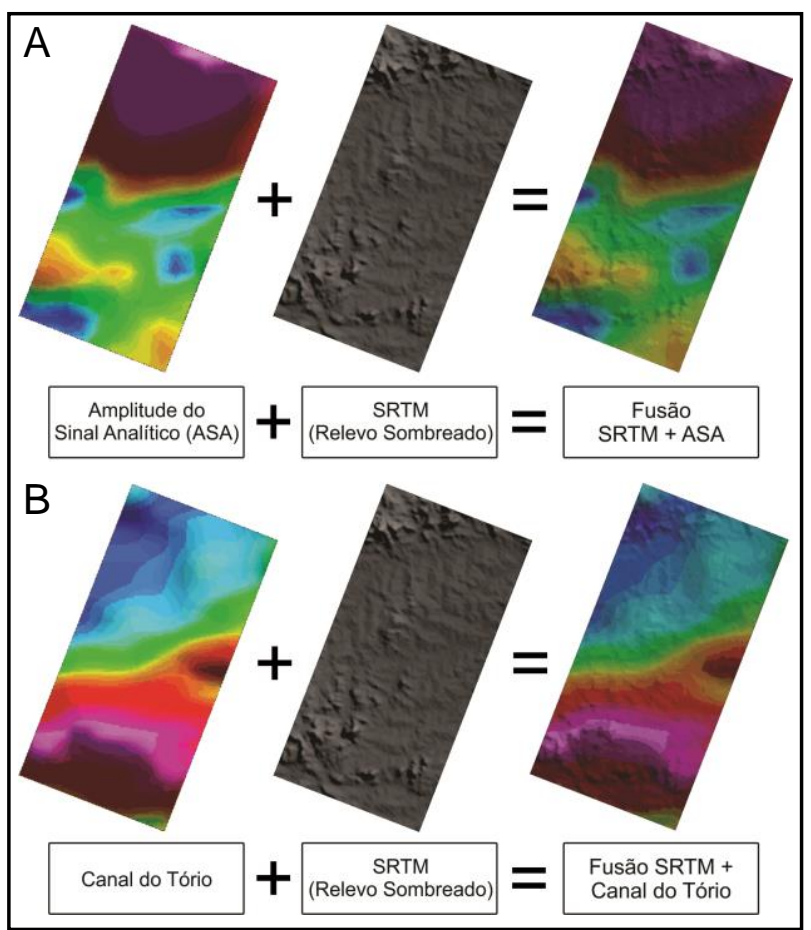

Figura 2 - Esquema mostrando como as imagens

SRTM e aerogeofísicas foram fundidas.

A) SRTM + Amplitude do Sinal Analítico;

B) SRTM + Canal do Tório.

\section{Contexto Geológico Regional}

O Terreno Granito-Greenstone de Rio Maria (TTGRM) está inserido nos domínios da Província Amazônia Central (Tassinari \& Macambira, 2004) ou Província Carajás (Santos, 2003), na porção sudeste do Cráton Amazônico. É composta por sequências metavulcanosedimentares do tipo greenstone belt e por diversos granitoides de idades arqueana.

Os terrenos granito-greenstone são compostos por sequências metavulcano-sedimentares do tipo greenstone belt e associações trondhjemito, tonalito e granodiorito (TTG). Esses terrenos são encontrados em diversas partes do mundo, como, por exemplo, nos blocos de Yilgarn e Pilbara, no oeste da Austrália, no cráton Kaapvaal, África do Sul e no Cráton Amazônico, no Brasil (Gill, 2014).

\section{Resultados}

Todas as imagens envolvidas neste trabalho foram analisadas individualmente e também de maneira integrada. De ambas as formas, a análise dessas imagens permitiu que fossem gerados produtos que auxiliaram no mapeamento geológico da área de estudo, tais como mapa geomorfológico, mapa de fotolineamentos, mapa planialtimétrico e mapa de domínios litogeofísicos. Além disso, durante todo o estudo foram feitas pesquisas na bibliografia referente à área de estudo e os mapas existentes em escalas de menor detalhe, bem como dissertações e teses foram também considerados durante a análise dos referidos produtos.

Durante a fase de campo 52 pontos foram metodicamente analisados quanto a seus aspectos petrográficos e estruturais, 34 amostras de rochas foram coletadas e descritas macroscopicamente e 10 lâminas delgadas foram confeccionadas e descritas microscopicamente no Laboratório de Petrografia da Unifesspa. Além disso, perfis N-S também foram feitos durante a fase de campo já que há uma predominância das estruturas regionais na direção $\mathrm{E}-\mathrm{W}$. A escolha da direção dos perfis também foi feita com base na análise dos produtos integrados. As imagens aerogeofísicas mostravam variações tanto radiométricas quanto magnéticas na direção $\mathrm{N}-\mathrm{S}$. O relevo sombreado da imagem SRTM também mostrava que a forma do relevo estava, por vezes, ligado com as respostas geofísicas e, portanto, seria viável fazer perfis na direção N-S, considerando que seria a direção ideal para que fossem encontrados o maior número de litologias e estruturas.

A análise e interpretação das imagens e dos produtos gerados a partir dessas, juntamente com os dados de campo e dados da bibliografia, foram feitas de maneira integrada, permitindo, assim, a elaboração de um mapa geológico para a área de estudo (Figura 5), onde foram definidas de cinco unidades geológicas distintas, a saber: 1) Metavulcanossedimentar; 2) Tonalito/Trondhjemito; 3) Rocha Cumulática; 4) Trondhjemito/Granodiorito; 5) Leucomonzogranito/Leucosienogranito; e 6) Dique Máfico. O mapa litológico da Figura 3B serve para comparar as litologias encontradas durante os trabalhos de campo com as respostas radiométricas (Figura $3 \mathrm{~A}$ ) e magnéticas (Figura $3 \mathrm{C}$ ). As rochas pertencentes à unidade 5 foram muito bem delimitadas por apresentarem os mais altos valores radiométricos entre as unidades mapeadas. Esses limites foram confirmados e melhor delimitados durante o mapeamento de campo. As rochas dessa unidade são principalmente leucomonzogranitos e leucosienogranitos (Figuras 4A). Minerais radioativos como zircão e allanita foram encontrados durante análises microscópicas e descrição das lâminas delgadas confeccionadas a partir dessas rochas (Figura 4B), justificando a alta resposta radiométrica. Quanto às rochas pertencentes à unidade 1 , essas foram bem delimitadas por apresentarem um modelado de dissecação estrutural formado por morros com topos angulosos, combinados com os maiores valores magnéticos entre todas as unidades. Essa unidade é rica em minerais ferromagnéticos como a magnetita. Cristais de magnetita foram encontrados em diversas rochas dessa unidade durante os trabalhos de campo (Figura 4C), bem como durante a análise e descrição das lâminas delgadas confeccionadas a partir dessas rochas (Figura 4D). A fase de campo confirmou o limite entre as rochas metavulcânicas supramencionadas e os granitoides adjacentes. As rochas das unidades 2 (Figura 4E) e 4 (Figura 4F) possuem composição química relativamente semelhante e por essa razão não apresentaram grandes diferenças nas respostas geofísicas, mas, ainda assim, o relevo e as respostas 
geofísicas variam levemente e ajudaram definir o limite entre essas duas unidades. Esse limite foi melhor definido com petrografia e principalmente a partir da análise de dados estruturais coletados durante a fase de campo. As rochas pertencentes às unidades 3 (Figura 4G) e 6 (Figura $4 \mathrm{H}$ ) foram as únicas que não apresentaram nenhuma resposta específica visível por conta da baixa resolução do dados geofísicos.

\section{Discussão e Conclusões}

A integração e análise dos dados geofísicos e SRTM se mostrou bastante útil no mapeamento geológico da área de estudo, principalmente no sentido de orientar os trabalhos de campo bem como na delimitação e diferenciação das unidades geológicas. Ao final deste trabalho, elaborou-se um mapa geológico para a área de estudo (Figura 5). A maior limitação dos dados geofísicos foi sua baixa resolução, pois, no caso das rochas pertencentes às unidades 3 (Dique Máfico) e 6 (Rocha Cumulática), os dados não apresentaram nenhuma resposta específica visível que pudesse sugerir uma investigação mais detalhada durante o mapeamento em campo. Dados geofísicos com maiores resoluções podem perfeitamente detectar diques e megaenclaves, dependendo das dimensões dos mesmos. A integração e análise de dados multifontes não substitui os trabalhos de campo, mas são ferramentas que os tornam mais eficientes, sendo, assim, de fundamental importância o uso combinado dos ambos.

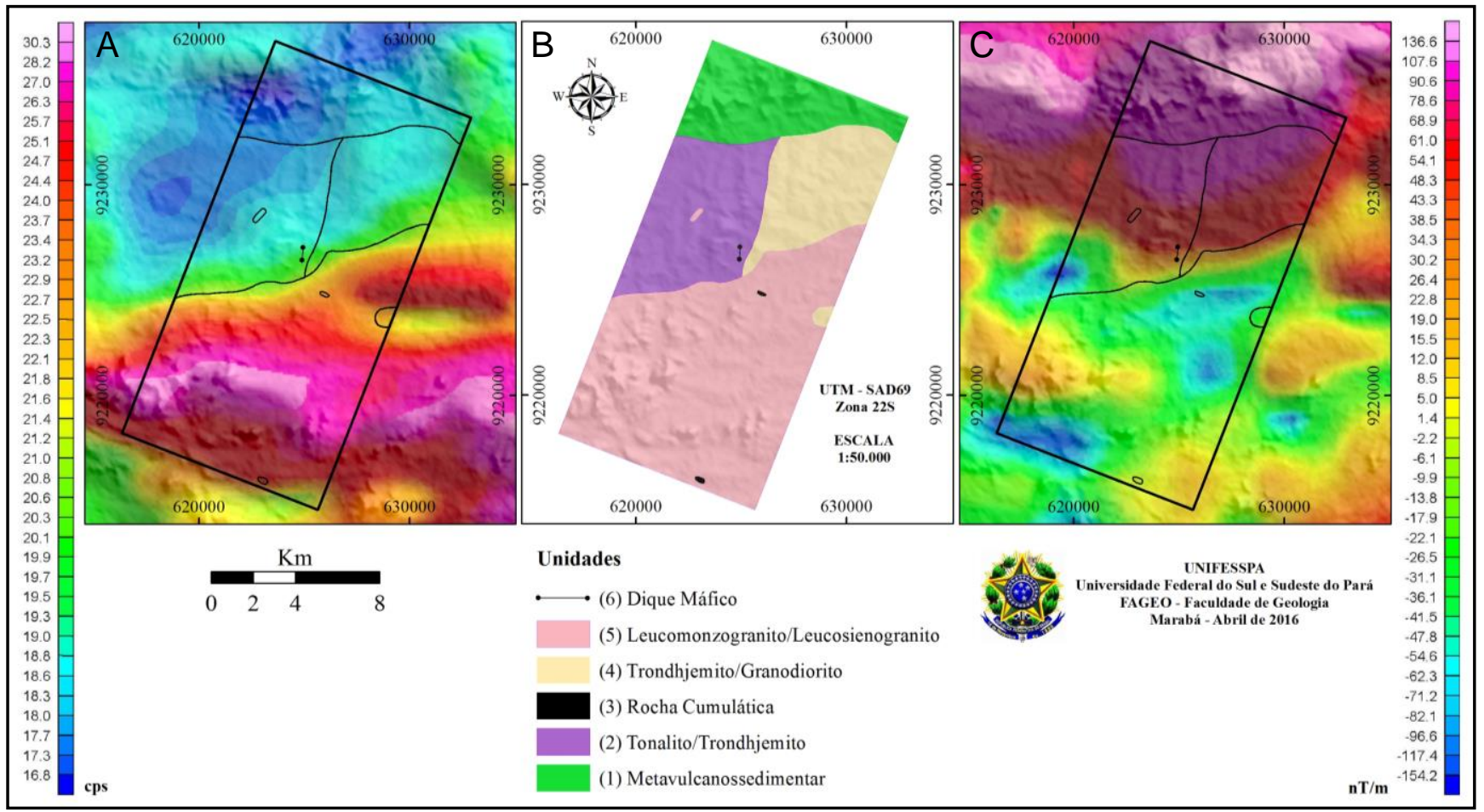

Figura 3: Respostas aerogeofísicas para comparação com as unidades encontradas durante o mapeamento. A) Canal do Tório + SRTM; B) Mapa de litologias; e C) Sinal Analítico + SRTM. 


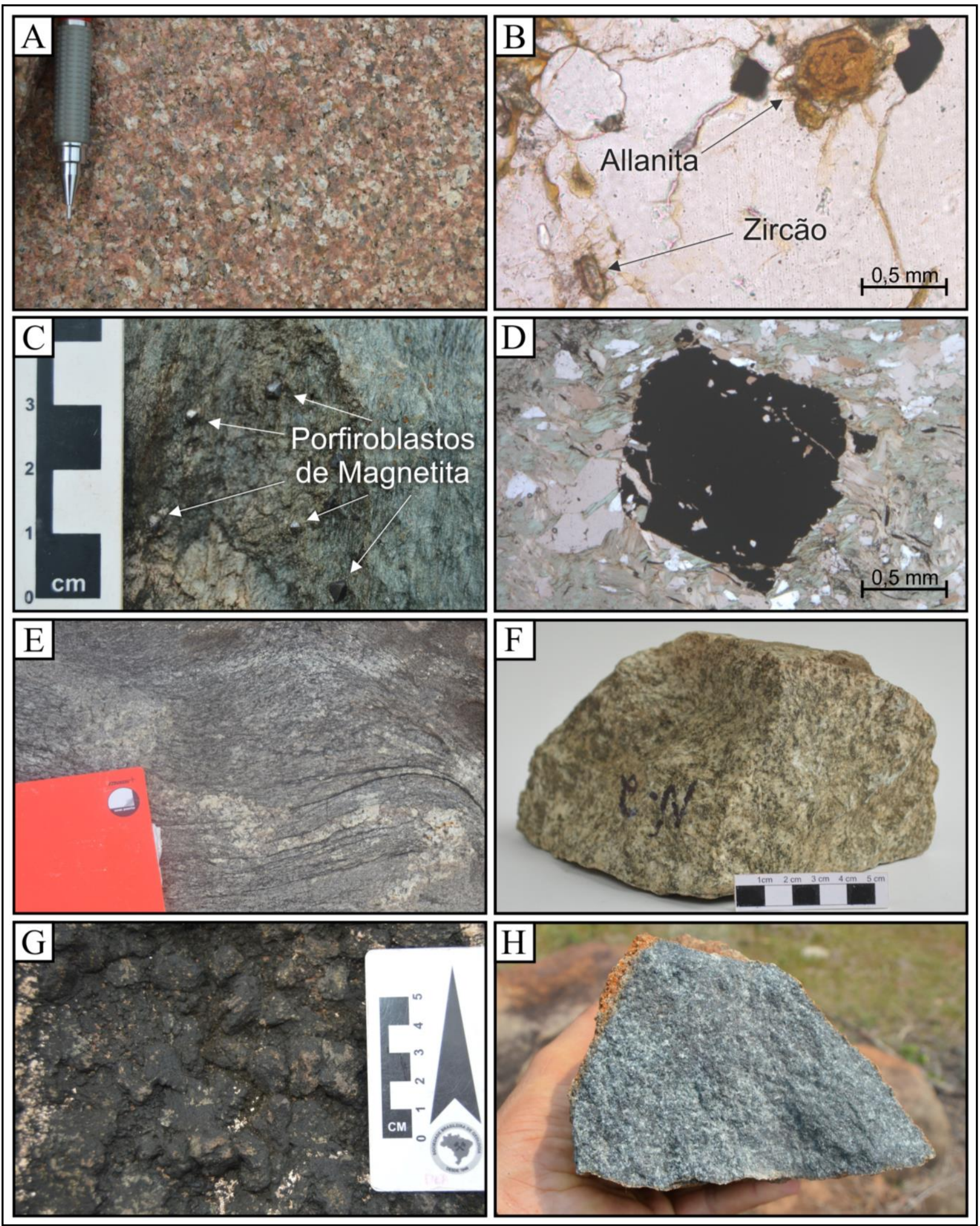

Figura 4: A) Leucogranito pertencente à unidade 5; B) Fotomicrografia de minerais portadores de elementos radioativos de rocha da unidade 5; C) Aspecto geral das rochas da unidade 2; D) Amostra de mão de rocha da unidade 4;

E) Cloritito com porfiroblastos de magnetita pertencente à unidade 1; F) Fotomicrografia de porfiroblasto de magnetita envolto por minerais de clorita; G) Textura cumulática de rocha da unidade Rocha Cumulática;

H) Amostra de mão de rocha do dique máfico. 


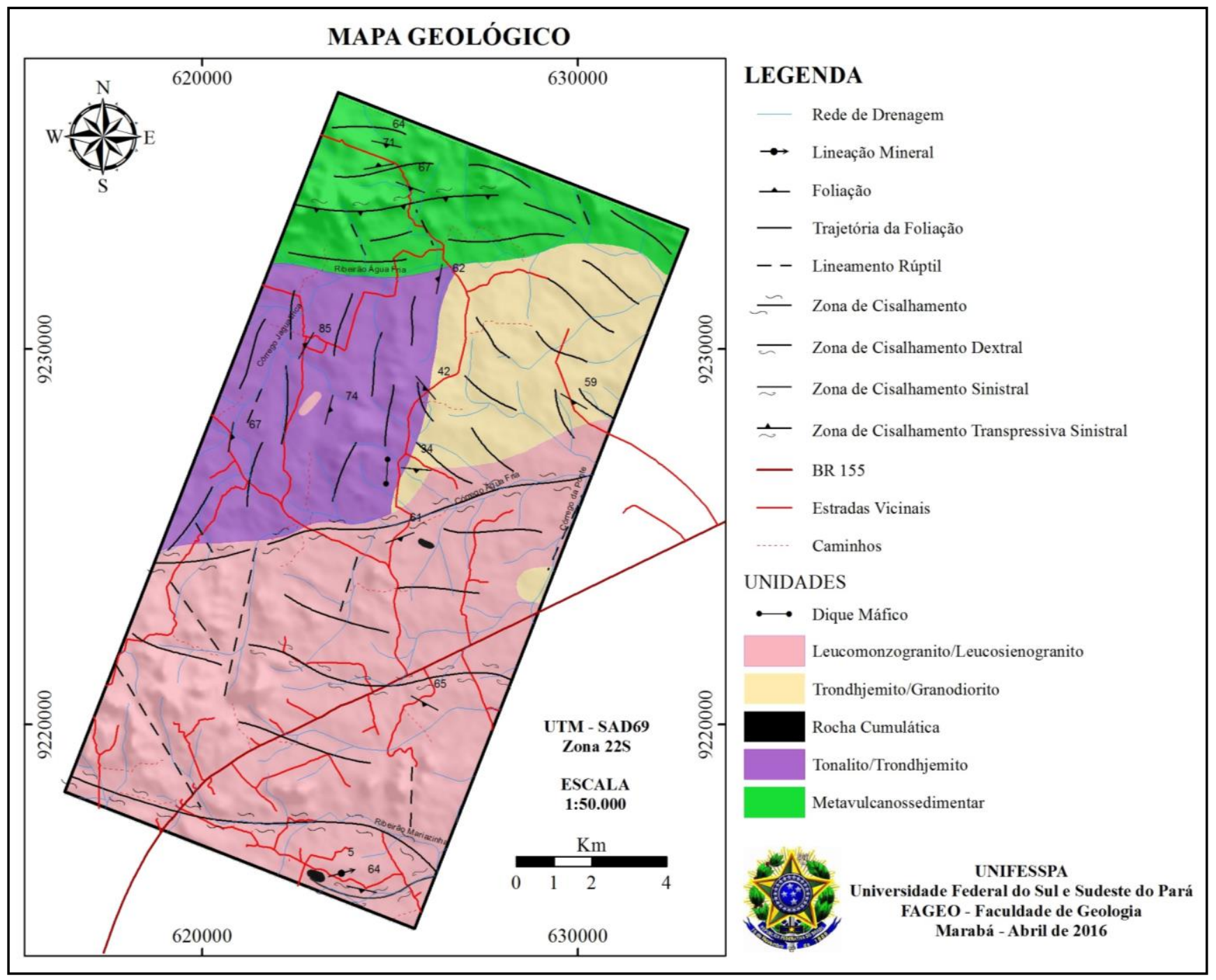

Figura 5: Mapa geológico elaborado para a área de estudo.

\section{Agradecimentos}

Os autores agradecem os professores da Faculdade de Geologia, Daniel Silvestre e Márgia de Souza, pelo apoio durante a etapa de campo, bem como aos colegas Kelly Cruz, Mônica de Paula, Filipe Araújo e George Bicalho.

\section{Referências}

Carneiro C. C., Crósta A. P., Silva A. M., Pinheiro R. V. L. 2006. Fusão de imagens altimétricas e aeromagnetométricas como ferramenta de interpretação geológica, exemplo da Província Mineral de Carajás (PA). Revista Brasileira de Geofísica, 24(2):261-271.

Cunha, E. R. S. P. Integração digital de imagens de radar e Landsat-TM com dados geológicos e aerogamaespectrométricos no auxílio ao mapeamento geológico da região do complexo granítico estrela-Pará (PA) / E. R. S. P. Cunha. São José dos Campos:

INPE, 2002. 147p. - (INPE-9858-TDI/868).
Gill R. 2014. Rochas e processos ígneos: um guia prático. Ed. Bookman, Porto Alegre, 427pp.

Santos J.O.S., 2003. Geotectônica dos Escudos das Guianas e Brasil-Central. In: L. A. Bizzi, C. Schobbenhaus, R. M. Vidotti e J. H. Gonçalves (eds.). Geologia, Tectônica e Recursos Minerais do Brasil. CPRM, Brasília, 169-195.

Tassinari C.C.G., Macambira M., 2004. A evolução tectônica do Craton Amazônico. In: Mantesso - Neto, V., Bartorelli, A., Carneiro, C.D.R., Brito Neves, B.B. (Eds.), Geologia do Continente Sul Americano: Evolução da obra de Fernando Flávio Marques Almeida. São Paulo, pp. 471-486. 